\title{
Astragalus saponins modulate mTOR and ERK signaling to promote apoptosis through the extrinsic pathway in HT-29 colon cancer cells
}

\author{
KATHY KA-WAI AUYEUNG ${ }^{1}$, NGA-LAI MOK ${ }^{1}$, CHING-MAN WONG ${ }^{2}$, \\ CHI-HIN $\mathrm{CHO}^{2}$ and JOSHUA KA-SHUN KO ${ }^{1}$ \\ ${ }^{1}$ Center for Cancer and Inflammation Research, School of Chinese Medicine, Hong Kong Baptist University; \\ ${ }^{2}$ School of Biomedical Sciences, Faculty of Medicine, The Chinese University of Hong Kong, Hong Kong SAR, P.R. China
}

Received February 24, 2010; Accepted April 22, 2010

DOI: 10.3892/ijmm_00000471

\begin{abstract}
We have previously demonstrated that the total saponins of Astragalus membranaceus (AST) possess potential anti-tumorigenic effects in human colon cancer cells and tumor xenografts. In the present study, the proapoptotic effects of AST were investigated in native and cytokine-induced HT-29 cells to further unveil its mechanism of action. Growthinhibitory action of AST $(60 \mu \mathrm{g} / \mathrm{ml})$ was demonstrated in native HT-29 cells, which was exaggerated in tumor necrosis factor (TNF) $(5 \mathrm{ng} / \mathrm{ml})$-induced cells. These were accompanied by caspase 3 activation, cleavage of poly(ADPribose) polymerase and a subsequent increase in apoptotic cell numbers. Furthermore, activation of procaspase 8 indicates that the extrinsic apoptotic pathway was involved, while cleavage of Bid into t-Bid implicates cross-talk with the intrinsic apoptotic pathway. Alternatively, AST caused S and G2/M phase arrest, while in cytokine-induced cells $S$ phase arrest was predominant. Further adding to our recent suggestion on its correlation with phosphatidylinositol 3kinase (PI3K)-Akt signaling, we have now revealed that AST caused overexpression of PTEN and down-regulation of mammalian target of rapamycin (mTOR) expression. Nevertheless, these events were preceded by a decrease in nuclear factor- $\kappa \mathrm{B}(\mathrm{NF}-\kappa \mathrm{B}) / \mathrm{DNA}$ binding activity with continuous ERK 1/2 activation. Some of these effects became more intense in cytokine-induced cells. Our findings in this study suggest that AST induces the extrinsic apoptotic cascade and causes cell cycle arrest in HT-29 cells by modulation of both mTOR and ERK signaling pathways, of which inhibition of NF-KB is important in the latter mechanism.
\end{abstract}

Correspondence to: Dr Joshua Ka-Shun Ko, Center for Cancer and Inflammation Research, School of Chinese Medicine, Hong Kong Baptist University, 7 Baptist University Road, Kowloon Tong, Hong Kong SAR, P.R. China

E-mail: jksko@hkbu.edu.hk

Key words: Astragalus saponins, mammalian target of rapamycin, extracellular signal-regulated protein kinase, nuclear factor- $\mathrm{\kappa B}$, tumor necrosis factor- $\alpha$, HT-29 cells
Most of the above processes are more pronounced in cytokineinduced cells.

\section{Introduction}

Radix Astragali is the dried root of Astragalus membranaceus Bunge var. mongholicus (Dge.) Hsiao, which is found in the Shanxi, Inner Mongolia, Jilin and Hebei provinces of mainland China. Many pharmacological studies have been conducted in Radix Astragali, among these its immunomodulatory and cardioprotective effects were most widely studied. It can suppress hypersensitivity and enhance the production of IgM antibodies $(1,2)$. There is growing evidence that Radix Astragali has the potential for treating human cancers (3). The main constituents of Radix Astragali include flavonoids (isoquercitrin, calycosin, odoratin), cycloartane triterpene saponins (astragalosides I-VIII, acetyl-astragaloside I, soyasaponin I, isoastragalosides I-II) and polysaccharides (4-7). We have recently discovered that the total Astragalus saponins (AST) exhibit anti-tumorigenic activities in both colon cancer cells and tumor xenografts (8). Nonetheless, the precise mechanism of AST action remains unexplored.

Failure in undergoing programmed cell death can lead to development of many diseases, including cancers (9). Mutation and deletion of apoptotic genes (e.g. p53, Bcl-2) play important roles in human carcinogenesis. As a result, apoptosis has been suggested as a potential target for cancer treatment (10). The induction of apoptosis occurs via two major pathways, the death receptor-activated (extrinsic) pathway through binding of ligands and the mitochondrion (intrinsic) pathway which is induced by several factors such as free radical or DNA damage (11). The extrinsic pathway plays an important role in the elimination of unwanted cells by the immune system, while the intrinsic pathway is important in the elimination of damaged cells that have undergone intracellular stress. Ligand binding of tumor necrosis factor (TNF)- $\alpha$, TNF-related apoptosis-inducing ligand (TRAIL) or Fas-ligand to their receptors in association with adaptor molecules Fas-associated death domain (FADD) and TNF receptor-associated death domain (TRADD) proteins in the cytoplasm lead to the formation of death-inducing signaling complex (DISC) and summon (inactive pro-enzyme form of caspase 8 and sometimes 
the initiator caspase 10). Finally, executioner caspases 3, 6 and 7 are cleaved and activated (12). Poly(ADP-ribose) polymerase (PARP) is a cleaved product of caspase 3 that can be used as an indicator of apoptosis (13). It has been reported to play a pivotal role in the DNA repair mechanism (14). Besides, caspase 8 can cleave $\mathrm{Bid}$ after the death receptor ligation, which facilitates its post-translational $\mathrm{N}$-myristoylation (15). Truncated Bid (t-Bid) is then translocated from cytosol to mitochondria, where cytochrome $\mathrm{c}$ is released by interaction with another proapototic protein Bax (in the intrinsic pathway). The cleavage of Bid is also believed to be responsible for the amplification of downstream effector events in the extrinsic apoptotic pathway (10).

In the present study, we aimed to elucidate the proapoptotic mechanism of AST by modulating a mammalian target of rapamycin (mTOR) and extracellular signal-regulated protein kinase (ERK) signaling, and proposed nuclear factor- $\kappa \mathrm{B}$ $(\mathrm{NF}-\mathrm{\kappa B})$ as the mediator involved in the apoptotoic process in native or cytokine-induced HT-29 colon cancer cells.

\section{Materials and methods}

Cell culture and drug treatments. HT-29 human colon adenocarcinoma cells (ATCC, Manassa, VA) were cultured in Dulbecco's modified Eagle medium (DMEM) supplemented with $10 \%$ heat-inactivated fetal bovine serum (FBS) and $1 \%$ penicillin-streptomycin (Gibco, Carlsbad, $\mathrm{CA}$ ) at $5 \% \mathrm{CO}_{2}$ and $37^{\circ} \mathrm{C}$. Cells were seeded at a density of $3-4 \times 10^{5}$ overnight, and then pre-incubated with $60 \mu \mathrm{g} / \mathrm{ml}$ of AST for $1 \mathrm{~h}$, with or without subsequent addition of $5 \mathrm{ng} / \mathrm{ml} \mathrm{TNF-} \alpha$ (cytokineinduced cells). All cells were harvested at 12, 24, 48 or $72 \mathrm{~h}$ after AST treatment. Extraction of AST from crude Radix Astragali was described previously (8). Chemicals were obtained from Sigma-Aldrich (St. Louis, MO) unless specified otherwise.

MTT cell viability assay. Cells were seeded at a density of $3 \times 10^{3}$ in 96 -well plates. MTT assay was conducted at $12-72 \mathrm{~h}$ after drug treatment. 3-(4,5-Dimethylthiazol-2-yl)-2,5-diphenyltetrazolium bromide (MTT) solution was added to wells and incubated for $3 \mathrm{~h}$. Solution in wells was aspirated and dimethyl sulfoxide (DMSO) was added. Absorbance was measured spectrophotometrically at $540 \mathrm{~nm}$.

Western immunoblotting. Cells were harvested and centrifuged. Cell pellets were collected and washed with ice-cold PBS (137 mM NaCl, $2.68 \mathrm{mM} \mathrm{KCl,} 8.1 \mathrm{mM} \mathrm{Na} 2 \mathrm{HPO}_{4}, 1.47 \mathrm{mM}$ $\mathrm{KH}_{2} \mathrm{PO}_{4}, \mathrm{pH}$ 7.4). They were then lysed in RIPA buffer [0.5\% deoxycholate, $0.1 \%$ SDS, $1 \%$ Triton $\mathrm{X}-100,10 \%$ glycerol, $50 \mathrm{mM}$ Tris, pH 7.5, $150 \mathrm{mM} \mathrm{NaCl}, 2 \mathrm{mM}$ EDTA, with $1 \mathrm{mM}$ phenylmethyl-sulfonyl fluoride (PMSF) and $10 \mu \mathrm{g} / \mathrm{ml}$ aprotinin] on ice for $30 \mathrm{~min}$. The supernatant was obtained by centrifugation at $14,000 \mathrm{x}$ g for $15 \mathrm{~min}$ at $4^{\circ} \mathrm{C}$. Proteins were quantified using Coomassie plus Protein Assay Reagent kit (Pierce, Rockford, IL). Samples were separated on 8-15\% SDS-polyacrylamide gel by electrophoresis and blotted onto nitrocellulose membrane for immunoblotting. Nitrocellulose membrane was then blocked in 5\% non-fat milk or $2 \%$ BSA in 1x TBST ( 2 mM Tris-Cl, $0.08 \% \mathrm{NaCl}, 0.1 \%$ Tween-20) for $45 \mathrm{~min}$. Membrane was washed with 1x TBST and then immunoblotted with the respective primary antibodies with the dilution of $1: 1,000$ in $0.2 \%$ of BSA in $1 \mathrm{x}$ TBS overnight at $4^{\circ} \mathrm{C}$. After washing with $1 \mathrm{x}$ TBST, corresponding secondary antibodies with the dilution of 1:3,000 was added and incubated for $1 \mathrm{~h}$. Bands were visualized by enhanced chemiluminescence (ECL) reagents (Amersham Bioscience, Piscataway, NJ) and exposed to Kodak X-Omat Blue XB-1 film (Rochester, NY). Results were analyzed by using the Quantity One version 4.4.1 Basic software (BioRad, Hercules, CA). The membrane was reprobed to detect $\beta$-actin as an internal control.

Immunofluorescence nuclear staining. Cells were seeded in 35-mm dishes and treated as stated above. They were washed with PBS twice and fixed in $4 \%$ paraformaldehyde for $10 \mathrm{~min}$. After washing with PBS three times, cells were permeated with ice-cold $75 \%$ methanol at $-20^{\circ} \mathrm{C}$ for another $5 \mathrm{~min}$. Cells were then stained with DNA binding dye bis Benzimide H33342 trihydrochloride for $10 \mathrm{~min}$. Nuclear morphology was observed under a fluorescence microscope (NanoDrop Technologies, Inc., Wilmington, DE) with magnification of $\mathrm{x} 400$. For detection of NF- $\mathrm{kB}$ nuclear translocation, cells were washed with PBS twice and blocked with $0.2 \%$ BSA at room temperature. After three washes with PBS, rabbit polyclonal antibody against p65 (1:100 dilution) were added and incubated overnight at $4^{\circ} \mathrm{C}$. Following three washes of PBS, anti-rabbit secondary antibody was added and incubated for $1 \mathrm{~h}$ at room temperature. Immunofluorescence images were observed under fluorescence microscope with magnification of $\mathrm{x} 400$.

Electrophoretic mobility shift assay (EMSA). Drug-treated cells were harvested and resulting pellets were collected and washed with ice-cold PBS twice. They were then re-suspended in $700 \mu 1$ of Buffer A [10 mM HEPES, pH 7.9, $10 \mathrm{mM} \mathrm{KCl,}$ $0.1 \mathrm{mM}$ EDTA, $0.1 \mathrm{mM}$ EGTA, $1 \mathrm{mM}$ dithiothreitol (DTT) and $0.5 \mathrm{mM}$ PMSF] and incubated on ice for $15 \mathrm{~min}$. One percent Nonidet P-40 (5 $\mu 1)$ was then added and vortexed for $15 \mathrm{sec}$. Supernatant containing cytosolic protein was removed by centrifugation at $15,000 \mathrm{x}$ g for $15 \mathrm{~min}$. Buffer C (20 mM HEPES, pH 7.9, 0.4 M NaCl, 1 mM EDTA, 1 mM EGTA, $1 \mathrm{mM}$ DDT and $1 \mathrm{mM}$ PMSF) was then added to re-suspend pellets and incubated on ice for $30 \mathrm{~min}$ to extract nuclear proteins. Supernatant was collected by centrifugation at $15,000 \mathrm{x} g$ for $15 \mathrm{~min}$. Protein concentration was measured according to the protein assay mentioned above. For labeling the NF- $\mathrm{KB}$ double-stranded oilgonucleotides, a probe with binding sites for NF- $\mathrm{kB}$ was used, with the following sequence, 5'-AGTTGAGGGGACTTTCCCAGGC-3'. The probe was incubated with T4 polynucleotide kinase buffer, $\gamma-{ }^{32} \mathrm{P}-\mathrm{ATP}$ $(3,000 \mathrm{Ci} / \mathrm{mmol}$ at $10 \mathrm{mCi} / \mathrm{ml})$ and $\mathrm{T} 4$ polynucleotide kinase (Invitrogen, Carlsbad, CA) at $37^{\circ} \mathrm{C}$ for $10 \mathrm{~min}$. Afterwards, $0.5 \mathrm{M}$ EDTA was added followed by adding TE buffer. The radioactively-labeled probe was purified by passing through the column (MicroSpin ${ }^{\mathrm{TM}}$ G-25 column, UK) twice and centrifuged at $1,000 \mathrm{x} \mathrm{g}$ for $2 \mathrm{~min}$ at $4^{\circ} \mathrm{C}$, before being stored at $-20^{\circ} \mathrm{C}$. To perform the gel retardation assay, $10 \mu \mathrm{g}$ of the extracted nuclear protein was incubated with the reaction buffer for $15 \mathrm{~min}$, followed by addition of the ${ }^{32} \mathrm{P}$ end-labeled oligonucleotide. Reaction mixture was separated in a nondenaturing $6 \%$ polyacrylamide gel. The gel was dried and exposed to radiographic film at $-70^{\circ} \mathrm{C}$. 


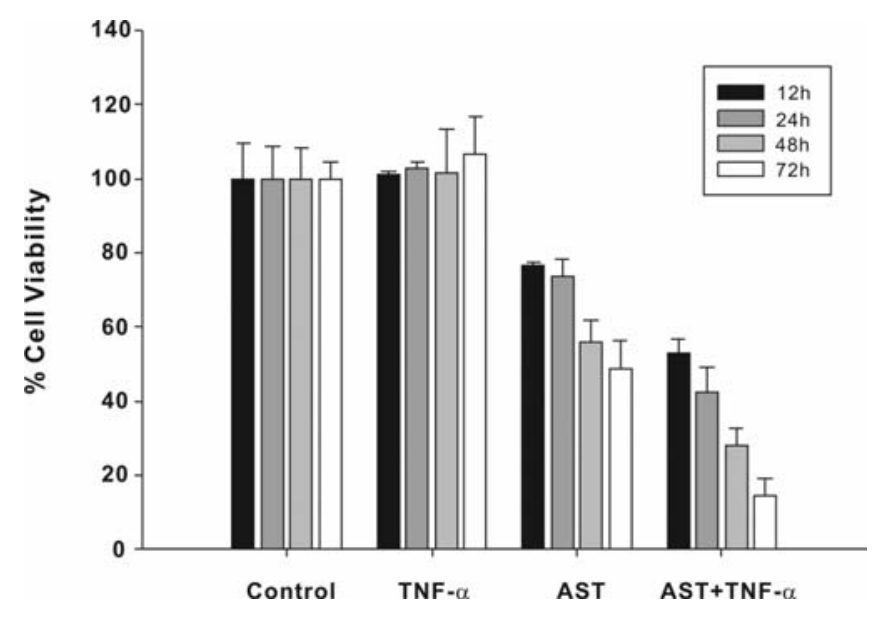

Figure 1. AST induces growth inhibition in HT-29 cells. HT-29 cells were treated with AST, TNF- $\alpha$ or AST plus TNF- $\alpha$ (TNF- $\alpha$ was added $1 \mathrm{~h}$ after AST) for 12, 24, 48 or $72 \mathrm{~h}$. Cell viability was determined by MTT assay. Results are expressed as percentage of viable cells in treatment groups with respect to the corresponding medium-treated controls. AST demonstrated a time-dependent cell growth inhibition in HT-29 cells, with further decrease in the viability of cells in cytokine-induced cells. Data are expressed as means \pm SEM of 4-6 experiments.

Flow cytometry. After drug treatment for $12,24,48$ or $72 \mathrm{~h}$, cells seeded at a density of $4 \times 10^{4}$ were collected by trypsinization with ice-cold PBS. Cells were then fixed with ice-cold $75 \%$ ethanol overnight at $-20^{\circ} \mathrm{C}$. Cell pellets were collected by centrifugation at $1,000 \mathrm{xg}$ for $10 \mathrm{~min}$ at $4^{\circ} \mathrm{C}$ the following day. Cells were then incubated with the master mix $[0.1 \%$ Triton X-100, $100 \mu \mathrm{g} / \mathrm{ml}$ RNase A and $50 \mu \mathrm{g} / \mathrm{ml}$ proidium iodide (PI) in PBS] for $1 \mathrm{~h}$ on ice for flow cytometry (FACS Canto $^{\mathrm{TM}}$ ) (BD Biosciences, Franklin Lakes, NJ). Cell distribution at different phases of the cell cycle with different treatments was determined by using PI staining.

Statistical analysis. Data are presented as mean \pm SEM and analyzed by using one-way analysis of variance (ANOVA), followed by an LSD post-hoc test (SPSS version 10.0; Chicago, IL). The level of statistical significance was established as $\mathrm{P}<0.05$.

\section{Results}

AST induces growth inhibition and apoptosis in native and cytokine-induced HT-29 cells. Survival rate of cells can be determined by the percentage of cell viability. There was a decrease in percentage of viable cells when cells were treated with AST in native or cytokine-induced cells (Fig. 1). There was no effect on cell viability when cells were treated with TNF- $\alpha$ alone. AST also exhibited a time-dependent growth inhibition in HT-29 cells, which was more pronounced in cytokine-induced cells.

Morphological change is an important feature that indicates apoptotic cell death. During apoptosis, the cell shrinks while the nucleus condenses and fragments, which can be observed by conducting immunofluorescence staining. Following AST treatment, cells became less rounded, shrunk in size and sometimes fragmented, with the observation of nuclear chromatin condensation (Fig. 2A). There was a significant (a)
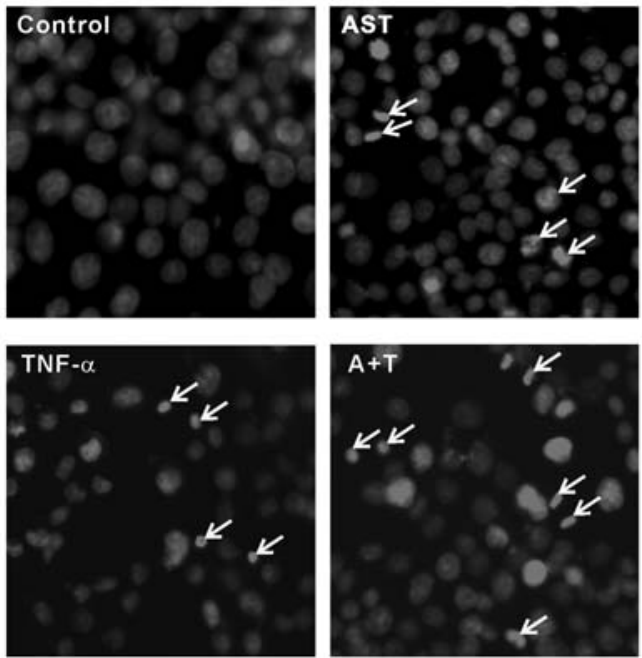

(b)

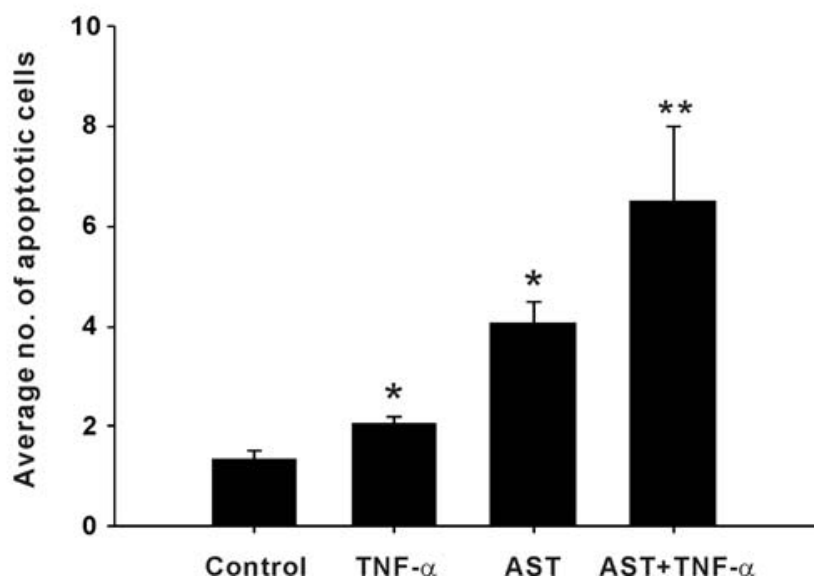

Figure 2. AST induces apoptosis in HT-29 cells. (A) Immunofluorescence staining of medium-treated cells (control, upper left panel) and cells treated with AST, TNF- $\alpha$ or AST + TNF- $\alpha(\mathrm{A}+\mathrm{T})$ under a fluorescence microscope (x400 amplification). Cells under apoptosis appear less rounded and smaller than normal with nuclear chromatin condensation. Apoptotic bodies (shown by arrows) were found in native or cytokine-induced cells treated with AST. (B) The number of apoptotic cells was counted after AST treatment for $72 \mathrm{~h}$ in 10 randomly-selected fields. An increased number of apoptotic cells occurred when cytokine-induced cells were treated with AST. Bars represent means \pm SEM of at least 3 experiments. ${ }^{*} \mathrm{P}<0.05 ;{ }^{* *} \mathrm{P}<0.01$. significantly different from corresponding control.

increase in the number of cells with condensed nuclei caused by AST in cytokine-induced cells (Fig. 2B).

AST modulates the extrinsic apoptotic cascade in native and cytokine-induced HT-29 cells. Procaspase 8 is the inactive pro-enzyme form of caspase 8 . After the ligation of death receptor, procaspase 8 cleaves to activate caspase 8 as manifested by reduced procaspase 8 expression. Our results show that AST induced downregulaton of procaspase 8 expression after 48 and $72 \mathrm{~h}$ of treatment (Fig. 3A). This effect became more prominent in cytokine-induced cells, of which the phenomenon was observed as early as $12 \mathrm{~h}$. Cleavage of procaspase 3 was designated to indicate the activation of caspase 3 , the key executioner caspase. The expression of procaspase 3 was shown to be decreased by 
(a)

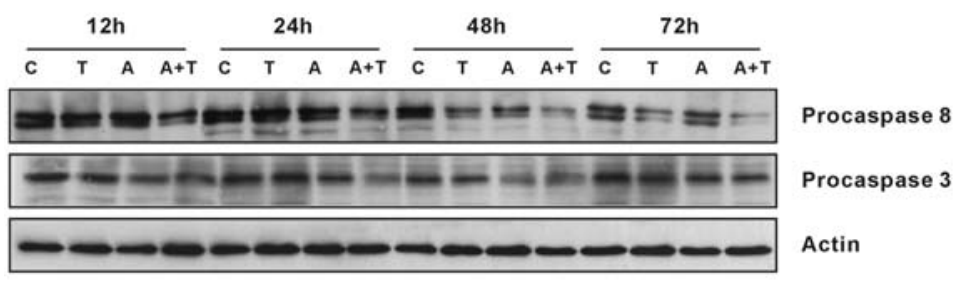

(b)

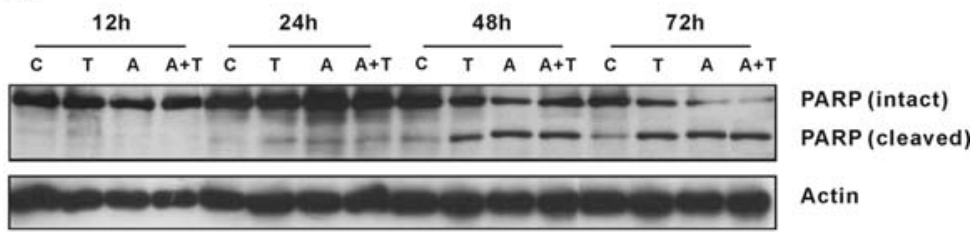

(c)

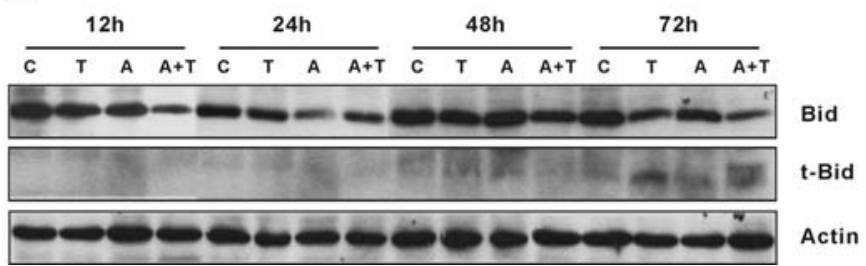

Figure 3. AST activates proapoptotic proteins in HT-29 cells. Cells were treated with AST (A), TNF- $\alpha$ (T) or AST + TNF- $\alpha$ (A+T) for $12,24,48$ or $72 \mathrm{~h}$. Concentrations of AST and TNF- $\alpha$ were $60 \mu \mathrm{g} / \mathrm{ml}$ and $5 \mathrm{ng} / \mathrm{ml}$, respectively. Untreated control cells (C) were incubated with culture medium only. Protein expression following drug treatments was measured by immunoblotting of cell extracts, whereas actin was used as internal control. (A) AST downregulated procaspase 8 expression at 48 and $72 \mathrm{~h}$, which was enhanced in cytokine-induced cells. Similarly, caspase 3 activation was resulted by AST treatment, with augmentation in cytokine-induced cells. (B) Cleavage of PARP, the substrate of caspase 3, occurred at the same time of caspase 3 activation. (C) AST downregulated Bid protein expression and formed t-Bid in native and cytokine-induced cells at $72 \mathrm{~h}$.

AST treatment. The effect was more obvious after $48 \mathrm{~h}$ and intensified in cytokine-induced cells. These events then resulted in increased PARP cleavage (Fig. 3B).

Bid is a pro-apoptotic $\mathrm{BH}-3$ protein that belongs to the Bcl-2 family. After activation of caspase 8, Bid is cleaved into truncated Bid (t-Bid) in order to amplify downstream extrinsic apoptotic pathway. The expression of intact Bid is thereby decreased during apoptosis. Our results have demonstrated that formation of t-Bid began after $48 \mathrm{~h}$ of AST treatment, while a clear increase in expression of t-Bid was observable at $72 \mathrm{~h}$. Such reduction became more significant in cytokineinduced colon cancer cells (Fig. 3C). In addition, the time of t-Bid formation actually matches that of the AST-evoked caspase 8 activation.

AST induces phase-specific cycle arrest in native and TNFtreated HT-29 cells through modulation of mTOR signaling. HT-29 colon cancer cells were treated with AST for 12, 24, 48 or $72 \mathrm{~h}$. Cells were accumulated at $S$ phase and arrested at G2/M phase after AST treatment for 24 and 48 h (Fig. 4). Also, $\mathrm{S}$ phase arrest resulted when treated with TNF- $\alpha$ alone. AST further increased the percentage of cells accumulated at the $\mathrm{S}$ phase in cytokine-induced cells (when compared to treatment of TNF- $\alpha$ alone). Nevertheless, cell cycle arrest was not sustained after drug treatment for $72 \mathrm{~h}$, when apoptosis was predominant.

mTOR is an intracellular nutrient sensor that controls protein synthesis, cell growth and metabolism. Inactivation of mTOR can induce autophagy. When mTOR is inactivated, its protein expression decreases. Our data show a reduction in p-mTOR expression following 12-72 h of AST treatment, with no alteration of mTOR expression (Fig. 5A). A similar observation was found in cytokine-induced cells, with no obvious synergistic/additive effect. AST could have inhibited mTOR to suppress growth and survival of colon cancer cells. PTEN is a tumor suppressor gene that is involved in the mTOR signaling pathway. Loss or mutation of PTEN can result in the development of many types of cancers. It has been reported that overexpression of PTEN stimulates autophagy. Our results indicate that expression of PTEN increased after AST treatment, which was slightly increased in cytokine-induced cells (Fig. 5A).

AST inhibits $N F-\kappa B / D N A$ binding activity in native and TNFtreated HT-29 cells that are associated with ERK activation. The NF-кB signaling pathway was found to be correlated with different types of cancer including that of the colon. It is also an important transcription factor that participates in colonic inflammation. We were interested to determine if AST affects $\mathrm{NF}-\kappa \mathrm{B}$ signaling in HT-29 cells. NF- $\mathrm{B} / \mathrm{DNA}$-binding activity in HT-29 cells was decreased after treatment of AST for 3-6 h, with further reduction in cytokine-induced cells. Nevertheless, the reduction began to level off after $24 \mathrm{~h}$ of drug treatment (Fig. 6A). In addition, both bis-benzimide H33342 stain and anti-p65 antibodies were added to HT-29 cell culture to investigate the intracellular localization of p65 following drug treatments. Under an unstimulated state, p65 was localized mainly in the cytoplasm with a visible red color. Upon stimuli 
$12 \mathrm{~h}$

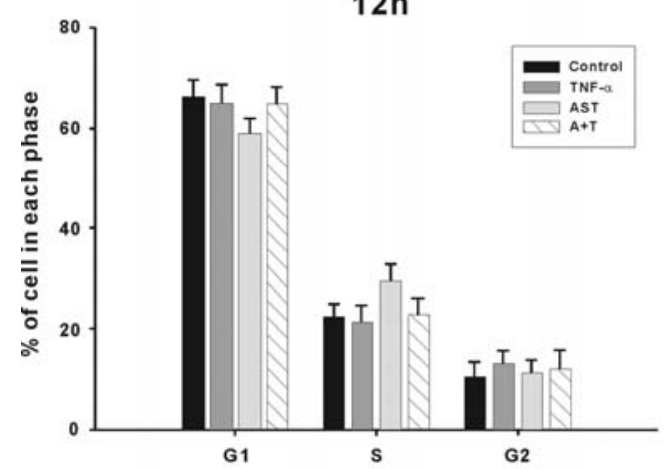

$48 \mathrm{~h}$

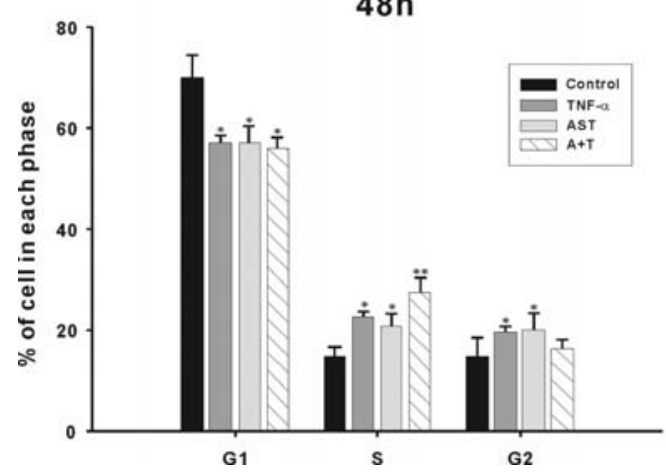

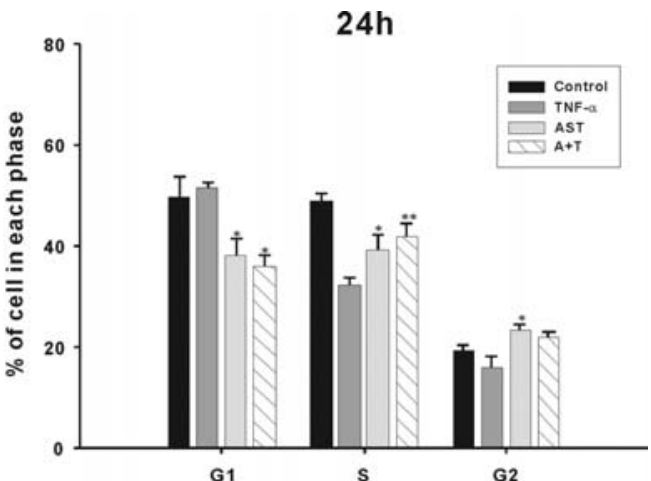

$72 \mathrm{~h}$

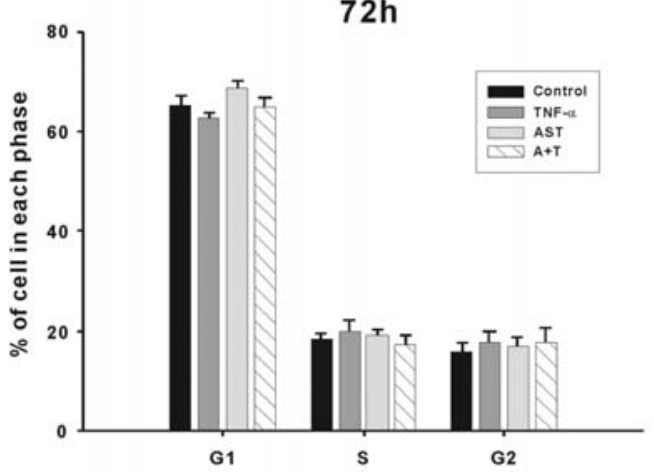

Figure 4. Cell distribution of HT-29 colon cancer cells in different phases of the cell cycle after 12, 24, 48 or $72 \mathrm{~h}$ of drug treatments. The percentage of cells in the $\mathrm{S}$ and G2/M phases was shown to be increased after AST treatment for 24 or $48 \mathrm{~h}$ (with concurrent reduction in the percentage of cells in the G1 phase). Cells treated with TNF- $\alpha$ caused cell arrest in the S phase, which became more prominent when AST was co-treated. However, cells were unable to remain arrested after $72 \mathrm{~h}$. Results are expressed as percentage of cells in each phase of the cell cycle in respect to the untreated control. Bars represent means \pm SEM of $2-3$ experiments. ${ }^{*} \mathrm{P}<0.05 ;{ }^{* * *} \mathrm{P}<0.01$, significantly different from the corresponding control.

(a)

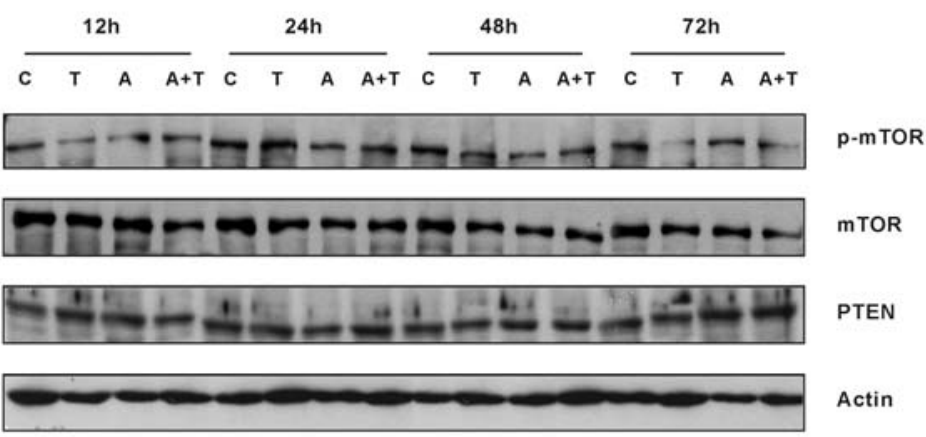

(b)

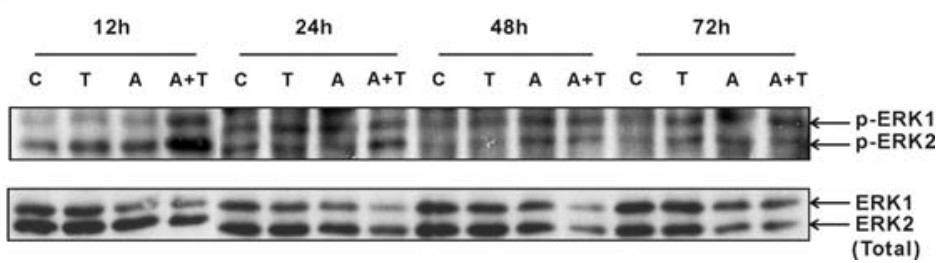

Figure 5. AST regulates mTOR, PTEN and ERK in HT-29 cells. HT-29 cells were treated with AST (A), TNF- $\alpha$ (T) or AST + TNF- $\alpha$ (A+T) for 12, 24, 48 or $72 \mathrm{~h}$. (A) AST downregulated phosphorylated mTOR expression without affecting mTOR and caused PTEN protein overexpression. These phenomena were not intensified in cytokine-induced cells. (B) Activation of ERK-1 and ERK-2 occurred after 12-72 h exposure to AST. The effect was boosted in cytokineinduced cells after $72 \mathrm{~h}$ of AST incubation. 
A
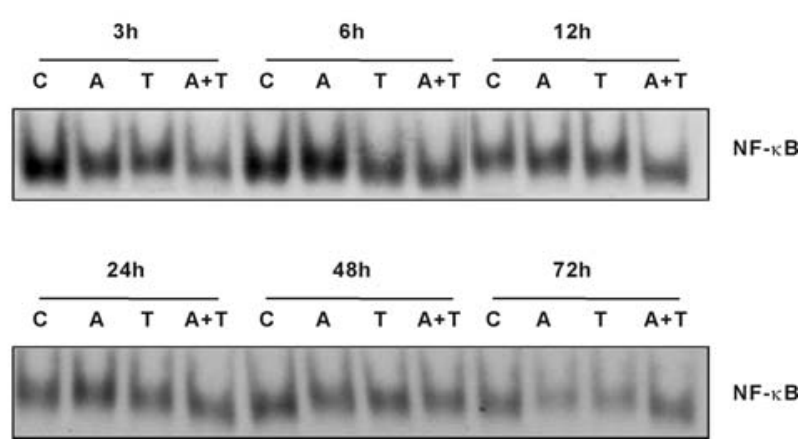

$N F-K B$

H33342

B

Control
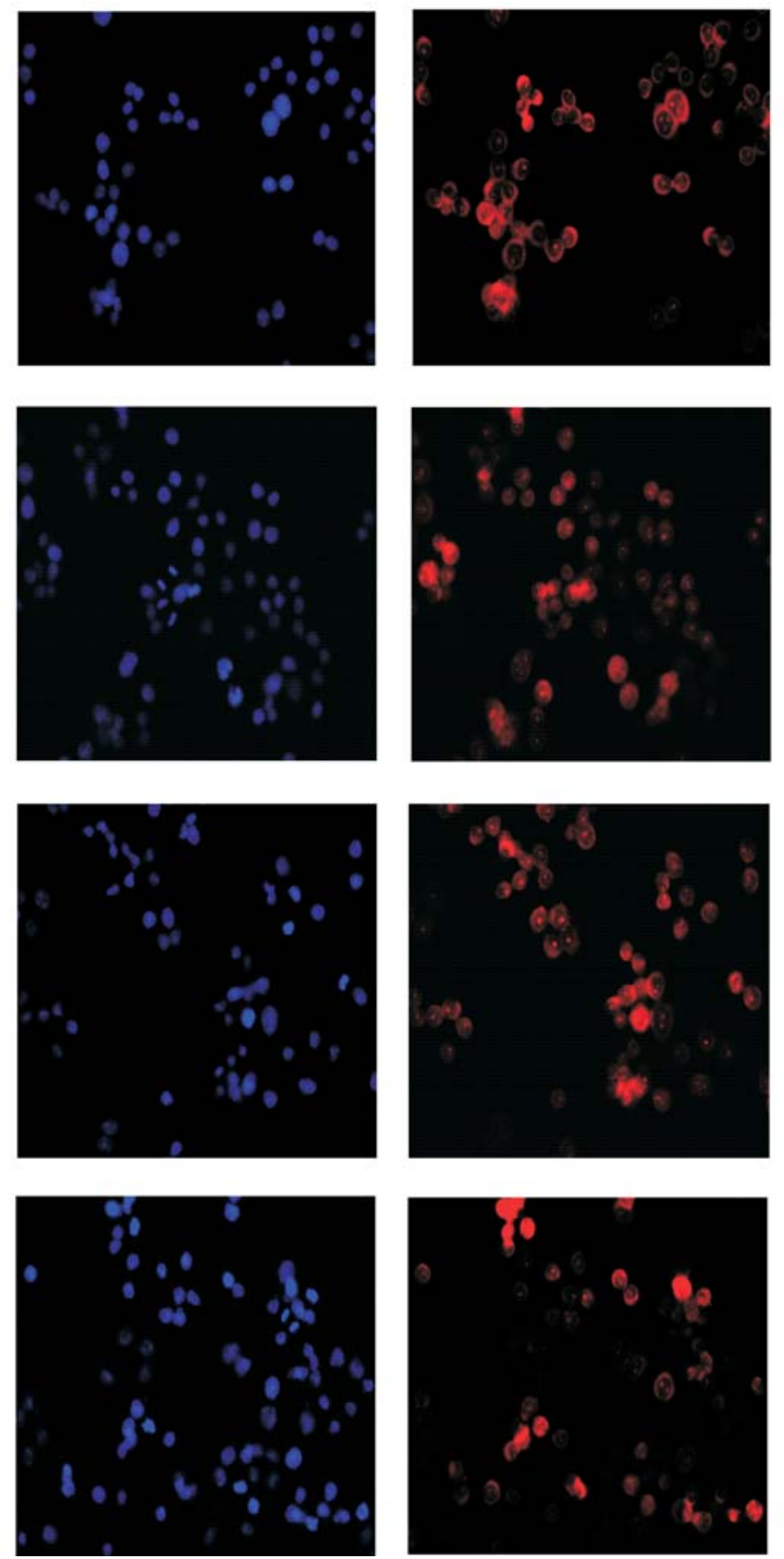

Merged
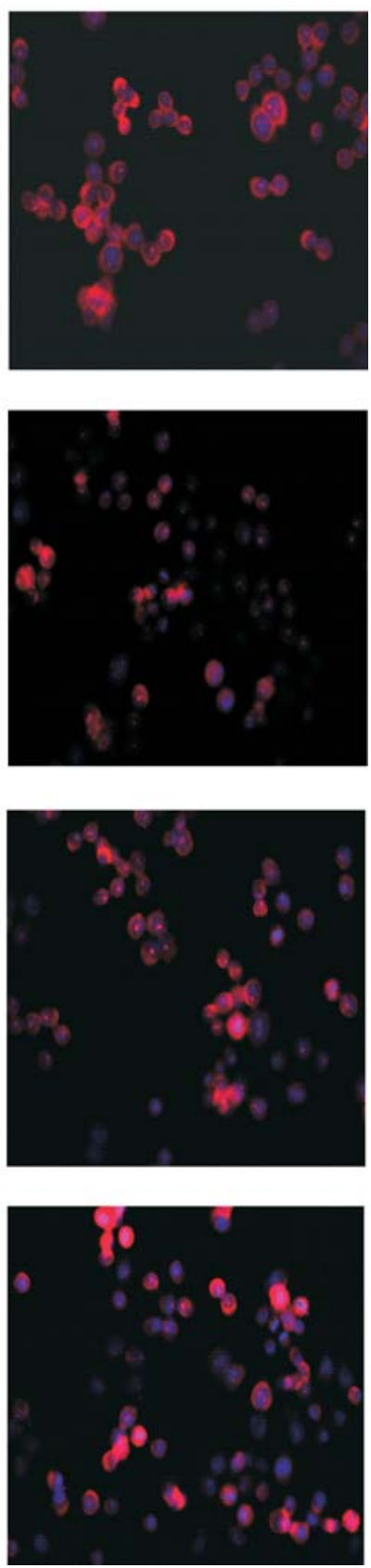

Figure 6. AST reduced NF-кB/DNA-binding activity in native and cytokine-induced HT-29 cells. (A) Effects of AST and/or TNF- $\alpha$ on NF- $\kappa$ B/DNA-binding activity after $3,6,12,24,48$ and $72 \mathrm{~h}$ of drug treatments in HT-29 cells were determined by EMSA. Concentrations of AST (A) and TNF- $\alpha$ (T) were $60 \mu \mathrm{g} / \mathrm{ml}$ and $5 \mathrm{ng} / \mathrm{ml}$, respectively. Control cells (C) were treated with culture medium alone without any drug treatment. NF- $\mathrm{B} / \mathrm{DNA}-\mathrm{binding}$ activity in HT-29 cells decreased prominently after incubated with AST for 3-12 h in both native and cytokine-induced cells, and the effects began to diminish thereafter. (B) HT-29 cells were treated with either $60 \mu \mathrm{g} / \mathrm{ml}$ of AST or $5 \mathrm{ng} / \mathrm{ml}$ of TNF- $\alpha$ or both for $12 \mathrm{~h}$. Cells were fixed and the intracellular location of the NF- $\mathrm{B}$ p65 subunit was determined by immunofluorescence staining using anti-p65 antibody. Pictures were taken with a fluorescence microscope (x400 magnification). Results show p65 nuclear translocation following AST treatment, which would be intensified in cytokine-induced cells. Similar effects were also observed at other time points but were most apparent at $12 \mathrm{~h}$. 
such as proinflammatory cytokine p65 would be translocated to the nucleus. The co-localization of red and blue (H33342) colors indicates the presence of apoptotic bodies with p65 nuclear translocation after $3 \mathrm{~h}$ of AST treatment. This phenomenon was intensified in cytokine-induced cells. The effect was most obvious after $12 \mathrm{~h}$ of AST incubation (Fig. 6B). This conflicts with the reduced NF-кB/DNA-binding activity that must be clarified later.

Increasing evidence has indicated that NF- $\mathrm{BB}$ activation is related to MAPK family members such as ERK. The effects of AST and TNF- $\alpha$ on the activation of ERK was examined as a possible signaling pathway. The expression of total ERK remains unchanged, while expression of both isoforms of phosphorylated ERK was upregulated after treatment with AST for 12-72 h, which was exaggerated in cytokine-induced cells (Fig. 5B). The continuous activation of ERK could have contributed to the proapoptotic activity of AST in colon cancer cells, which may be facilitated by earlier decrease in NF- $\mathrm{NB} /$ DNA-binding activity.

\section{Discussion}

Radix Astragali is a tonifying herb commonly used in traditional Chinese Medicine. It has been shown to possess antiproliferative effect on different cancer cell lines, including that of the colon (16). Astragalus saponins are one of the major groups of chemical constituents. We have demonstrated in a recent report that the total Astragalus saponin AST exerts antitumorigenic and proapoptotic actions in colon cancer cells and tumor xenografts (8). In the present study, we investigated the possible involvement of the mammalian target of rapamycin (mTOR) and extracellular signal-regulated protein kinase (ERK) signaling pathways in the proapopotic effects of AST in HT-29 colon cancer cells, focusing on the extrinsic apoptotic pathway. Recent studies have reported that caspase 8 is involved in the anti-tumor mechanism of SC-1 in Hep 3B cells, propolin A and B in human melanoma cells and RRR- $\gamma$ tocopherol in human breast cancer cells $(14,17,18)$. Furthermore, another study also showed that colon carcinoma cells with mutations of caspase 8 are less sensitive to druginduced apoptosis, of which restoration of caspase 8 expression could sensitize the resistant tumor cells for apoptosis (19). All these studies have suggested that caspase 8 plays an important role in the anti-carcinogenic mechanism. Procaspase 8 cleavage and subsequent activation of the downstream executioner caspase 3 were revealed after AST treatment, which resulted in drug-induced apoptosis. In addition, cleavage of the caspase 3 substrate PARP would facilitate cellular disassembly, leading to apoptosis (20). In contrast, following the ligation of the death receptor, caspase 8 cleaves intact Bid into its active form t-Bid, which in turn triggers the release of Bax to amplify downstream effector events in the intrinsic pathway by initiating release of apoptotic factors (e.g. cytochrome c) from mitochondria into the cytoplasm. Otherwise stated, Bid serves a key role in linking the intrinsic and extrinsic pathways to strengthen the apoptotic effects. Study of Zhou et al has re-confirmed this hypothesis, by indicating that Bid is important in the andrographolide-induced apoptotic signaling pathway of human cancer cells, as it relates the cell death signaling of caspase 8 to the mitochondria
(21). In fact, we have already reported that AST stimulates the intrinsic apoptotic pathway in human cancer cells (22).

mTOR is a 289-kd phosphatidylinositol 3-kinase (PI3K)related kinase which functions as an intracellular nutrient sensor that control protein synthesis, cell growth and metabolism. Dysregulation of mTOR signaling is involved in many human cancers such as carcinomas of lung, bladder, stomach and lymphomas. This suggests mTOR as a target of novel therapy for human cancers $(23,24)$. There are two mTOR complexes, mTOR complex 1 (mTORC1) and mTOR complex 2 (mTORC2), where mTORC1 is responsible for nutrient sensing signals and mTORC2 is implicated in actin organization and phosphorylates the Akt protein kinase B (23). Activation of Akt by mTORC2 drives several cancer-related response including increase in cell proliferation, growth and cell migration and a shift to glycolytic metabolism. Upstream regulation of mTOR will give rise to human diseases characterized by hamartomas with a variable propensity to progress into neoplasia (25). One of the essential upstream regulators for mTORC1 activation involves stimulation of Class I PI3Ks by members of the receptor tyrosine kinase family, which triggers the conversion of phosphatidylinositol-4,5-biphosphate $\left(\mathrm{PIP}_{2}\right)$ to the bioactive messenger phosphatidylinositol-3,4,5-triphosphate $\left(\mathrm{PIP}_{3}\right)$. This in turn causes subsequent activation of the serine-threonine kinase Akt (protein kinase B). Nevertheless, mTOR signaling has a dual role in the PI3K-Akt pathway, of which on the one hand mTORC2 is an upstream activator of Akt, while on the other hand mTORC1 is a downstream recipient of PI3K-Akt regulation. We have recently discovered that AST induces anti-carcinogenic effect at least partly by modulating PI3KAkt signaling (26). It is of interest to see if the upstream (e.g. PTEN) and downstream (e.g. mTOR from the mTORC1 complex) factors will also be regulated by AST. In this study, expression of mTOR was shown to be decreased in ASTtreated cells, which implicates that antitumor action of AST may also act through inhibition of cell proliferation which is regulated by the mTOR signaling pathway. PTEN (phosphatase and tensin homolog deleted on chromosome ten) is a tumor suppressor gene that is ubiquitously expressed in human tissues. A deficiency of PTEN leads to hyperactivation of the PI3K-Akt pathway, which is the cause for many cancers (25). It is one of the most frequently mutated tumor-suppressor genes and is impinging upon mTOR signaling. Inhibition of cell migration and invasion by directly dephosphorylating two key tyrosine-phosphorylated proteins is one of the functions of PTEN. PTEN also plays a key role in dephosphorylating a key signal transduction lipid. This lipid signal transduction pathway can protect tumor cells from apoptosis in the absence of PTEN. Thus, PTEN negatively regulates cell interactions with the extracellular matrix and maintains cell sensitivity to apoptosis. Recent studies have shown that restoration of PTEN increases the rate of apoptosis in glioma cells and induces apoptosis in breast cancer cell lines even in the presence of cell attachment $(27,28)$. A previous study has proven that overexpression of PTEN stimulates autophagy in colon cancer cells (29). Upregulation of PTEN following ASTtreatment has been demonstrated in our immunoblots.

The nuclear factor- $\mathrm{B}(\mathrm{NF}-\kappa \mathrm{B})$ pathway is involved in the regulation of key cellular processes such as proliferation, stress response, innate immunity and inflammation. Mutations and 
misregulation of NF- $\mathrm{NB}$ signaling have been implicated in a variety of cancers (30). It activates proliferation and inhibits apoptosis by activating modulators of cytokines (e.g. TNF- $\alpha$ ), growth factors, survival genes, angiogenic factors and inflammatory genes $(31,32)$. The NF-кB/REL family of transcription factors is comprised of Rel A/p65, c-Rel, Rel B, P105/NF-кB1 and p100/NF-кB2, whereas the most common combination is the $\mathrm{p} 65 / \mathrm{p} 50$ heterodimer (33). NF- $\mathrm{\kappa B}$ has been demonstrated to inhibit TNF- $\alpha$ induced cell death. TRAILinduced apoptosis in renal cancer can be prevented by activation of this transcription factor. Therefore, chemotherapeutic agents that activate $\mathrm{NF}-\kappa \mathrm{B}$ can accounted for the resistance of colon cancer cells to cytotoxic challenges $(34,35)$. Caspases can play an indirect role in the regulation of $\mathrm{NF}-\kappa \mathrm{B}$ activation, since $\mathrm{NF}-\kappa \mathrm{B}$ is substrate for caspase cleavage. Caspase-3-mediated cleavage of p65, p50 and c-Rel can be induced upon TNF- $\alpha$ activation (36). Immunofluorescence staining of HT-29 cells in our study showed nuclear condensation in AST- and TNF$\alpha$-treated cells, being most prominent at $72 \mathrm{~h}$. However, the manifestation of p65 nuclear translocation during early

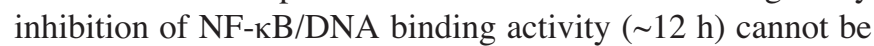
explained and the discrepancy remains to be clarified. NF- $\mathrm{B}$ activity is mainly controlled by $\mathrm{I} \kappa \mathrm{B}$ inhibitor proteins. Inflammatory signals initiate the degradation of $\mathrm{I} \kappa \mathrm{B}$ by stimulating phosphorylation of serines-32 and -36 (37). It has been shown that the ERK induces site-specific phosphorylation of IкB- $\alpha$ in HeLa cells and directly activates the IKK complex (38). In contrast, the ERK signaling pathway involves a cascade of phosphorylation events and is generally regarded as cell proliferation- and differentiation-related (39). However, the role of ERK is controversial. Some stimuli may act through the ERK pathway to cause apoptosis, although the exact mechanism of ERK-caused apoptosis has yet to be elucidated. It has been suggested that transient ERK activation may be linked to cellular proliferation while strong and persistent activation may lead to programmed cell death (40). It is also proposed that ERK will mediate $\mathrm{NF}-\kappa \mathrm{B}$ during its proapoptotic action. Our data show that protein expression of both phosphorylated form of ERK-1 and ERK-2 are increased without any change of total ERK during 12-72 $\mathrm{h}$ of drug exposure, which indicates the crucial role of ERK in $\mathrm{NF}-\kappa \mathrm{B}$ signaling and the resulting apoptotic process.

Collectively, findings from our study indicate that AST induces growth-inhibition in HT-29 cells by activation of the extrinsic apoptotic cascade as well as facilitation of phasespecific cell cycle arrest. These events appear to be modulated by both mTOR and ERK signaling, of which NF-кB has played a role in the proapoptotic activities of the latter pathway. In most of the afore-mentioned processes, the effects of AST could be amplified in cytokine-induced cells.

\section{References}

1. Lee SJ, Oh SG, Seo SW, et al: Oral administration of Astragalus membranaceus inhibits the development of DNFB-induced dermatitis in NC/Nga mice. Biol Pharm Bull 30: 1468-2471, 2007.

2. Kajimura K, Takagi Y, Miyano K, et al: Polysaccharide of Astragali Radix enhance IgM antibody production in aged mice. Biol Pharm Bull 20: 1178-1182, 1997.

3. Kurashige S, Akuzawa Y and Endo F: Effects of Astragali Radix extract on carcinogenesis, cytokine production, and cytotoxicity in mice treated with a carcinogen, N-butyl-N'-butanolnitrosoamine. Cancer Invest 17: 30-35, 1999.
4. Xu F, Zhang Y, Xiao SY, et al: Absorption and metabolism of Astragali Radix decoction: in silico, in vitro, and a case study in vivo. Drug Metab Dispos 34: 913-924, 2006.

5. Kitagawa I, Wang HK, Saito M, Takagi A and Yoshikawa M: Saponin and sapogenol. XXXV. Chemical constituents of Astragali Radix, the root of Astragalus membranaceus Bunge. (2) Astragalosides I, II and IV, acetylastragaloside I and isoastragalosides I and II. Chem Pharm Bull 31: 698-708, 1983.

6. Yu QT, Qi LW, Li P, Yi L, Zhao J and Bi ZM: Determination of seventeen main flavonoids and saponins in the medicinal plant Huang-qi (Radix Astragali) by HPLC-DAD-ELSD. J Sep Sci 30: 1292-1299, 2007.

7. Zhang YW, Wu CY and Cheng JT: Merit of Astragalus polysaccharide in the improvement of early diabetic nephropathy with an effect on mRNA expressions of NF- $\mathrm{BB}$ and IкB in renal cortex of streptozotoxin-induced diabetic rats. J Ethnopharmacol 114: 387-392, 2007.

8. Tin MM, Cho CH, Chan K, James AE and Ko JK: Astragalus saponins induce growth inhibition and apoptosis in human colon cancer cells and tumor xenograft. Carcinogenesis 28: 1347-1355, 2007.

9. Millan A and Huerta S: Apoptosis-inducing factor and colon cancer. J Surg Res 151: 163-170, 2009.

10. Saikumar P, Dong Z, Mikhailov V, Denton M, Weinberg JM and Venkatachalam MA: Apoptosis: definition, mechanism, and relevance to disease. Experta Med 107: 489-506, 1999.

11. Maddika S, Ande SR, Panigrahi S, et al: Cell survival, cell death and cell cycle pathways are interconnected: Implication for cancer therapy. Drug Resist Updates 10: 13-29, 2007.

12. Huerta S, Goulet EJ and Livingston EH: Colon cancer and apoptosis. Am J Surg 191: 517-526, 2006.

13. Bai M, Bai AP, Horianopoulos NO, Grepi C, Agnantis NJ and Kanavaros P: Expression of Bcl-2 family proteins and active caspase 3 in classical Hodgkin's lymphomas. Human Pathol 38: 103-113, 2006.

14. Su CL, Wu CJ, Chen FN, Wang BJ, Sheu SR and Won SJ: Supernatant of bacterial fermented soybean induces apoptosis of human hepatocellular carcinoma Hep 3B cells via activation of caspase 8 and mitochondria. Food Chem Toxicol 45: 303-314, 2006.

15. Kaufmann T, Tai L, Ekert PG, et al: The BH3-only protein Bid is dispensable for DNA damage- and replicative stress-induced apoptosis or cell-cycle arrest. Cell 129: 423-433, 2007.

16. Lin J, Dong HF, Oppenheim JJ and Howard OM: Effects of Astragali Radix on the growth of different cancer cell lines. World J Gastroenterol 9: 670-673, 2003.

17. Chen CN, Wu CL and Lin JK: Apoptosis of human melanoma cells induced by novel compounds propolin A and propalin B from Taiwanses propolis. Cancer Lett 245: 218-231, 2007.

18. Yu WP, Park SK, Jia L, et al: RRR- $\gamma$-tocopherol induces human breast cancer cells to undergo apoptosis via death receptor 5 (DR5)-mediated apoptotic signaling. Cancer Lett 259: 165-176, 2008.

19. Van Geelen CMM, de Vries EGE and de Jong S: Lessons from TRAIL-resistance mechanisms in colorectal cancer cells: paving the road to patient-tailored therapy. Drug Resist Updates 7: 345-358, 2004.

20. Kim SY, Park KW, Kim JY, et al: Thiosulfinates from Allium tuberosum $\mathrm{L}$. induce apoptosis via caspase-dependent and -independent pathways in PC-3 human prostate cancer cells. Bioorg Med Chem Lett 18: 199-204, 2008.

21. Zhou J, Zhang S, Ong CN and Shen HM: Critical role of proapoptotic Bcl-2 family members in andrographolide-induced apoptosis in human cancer cells. Biochem Pharmacol 72: 132-144, 2006.

22. Auyeung KKW, Law PC and Ko JKS: Astragalus saponins induces apoptosis via an ERK-independent NF- $\kappa \mathrm{B}$ signaling pathway in the human hepatocellular HepG2 cell line. Int J Mol Med 23: 189-196, 2009.

23. Cruzado JM: Non-immunosuppressive effects of mammalian target of rapamycin inhibitors. Transplant Rev 22: 73-81, 2008.

24. Huang $S$ and Houghton PT: Targeting mTOR signaling for cancer therapy. Current Opin Pharmacol 3: 371-377, 2003.

25. Chiang GG and Abraham RT: Targeting the mTOR signaling network in cancer. Trends Mol Med 13: 433-442, 2007.

26. Auyeung KK, Cho CH and Ko JKS: A novel anticancer effect of Astragalus saponins: transcriptional activation of NSAIDactivated gene. Int J Cancer 125: 1082-1091, 2009.

27. Geurtin DA and Sabatini DM: An expanding role for mTOR in cancer. Trend Mol Med 11: 354-361, 2005. 
28. Tamura M, Gu J, Tran $\mathrm{H}$ and Yamada KM: PTEN Gene and integrin signaling in cancer. J Natl Cancer Inst 22: 1820-1828, 1999.

29. Meijier AJ and Codogno P: Signalling and autophagy regulation in health, aging and disease. Mol Aspects Med 27: 411-425, 2006

30. Yu LL, Yu HG and Yu JP: Nuclear factor-кB p65 (RelA) transcription factor is constitutively activated in human colorectal carcinoma tissue. World J Gastroenterol 10: 55-60, 2004.

31. Dreesen O and Brivanlou AH: Signaling pathways in cancer and embryonic stem cells. Stem Cell Rev 3: 7-17, 2007.

32. Karin M: Nuclear factor-kappa B in cancer development and progression. Nature 441: 431-436, 2006.

33. Gadjeva M, Tomczak MF, Zhang M, et al: A role for NF-кB subunits p50 and p65 in the inhibition of lipopolysaccharideinduced shock. J Immunol 173: 5786-5793, 2004.

34. Colo GP, Rosato RR, Grant S and Costas MA: RAC3 downregulation sensitizes human chronic myeloid leukemia cells to TRAIL-induced apoptosis. FEBS Lett 581: 5075-5081, 2007.

35. Huerta S, Heinzerling JH, Anguiano-Hernandez YM, et al: Modification of gene products involved in resistance to apoptosis in metastatic colon cancer cells: role of Fas, Apaf-1, NF-кB, IAPs, Smac/DIABLO, and AIF. J Surg Res 142: 184 194, 2006.
36. Kucharczak J, Simmons MJ, Fan YJ and Gelinas C: To be, or not to be: NF- $\kappa B$ is the answer-role of Rel/NF- $\mathrm{BB}$ in the regulation of apoptosis. Oncogene 22: 8961-8982, 2003.

37. Karin M and Delhase M: The IкB kinase (IKK) and NF-кB: key elements of proinflammatory signalling. Sem Immunol 12: 85-98, 2000.

38. Lee SH, Lee CW, Lee JW, et al: Induction of apoptotic cell death by 2'-hydroxycinnamaldehyde is involved with ERK-dependent inactivation of NF-кB in TNF- $\alpha$ treated SW620 colon cancer cells. Biochem Pharmacol 70: 1147-1157, 2005.

39. Smalley KSM: A pivotal role for ERK in the oncogenic behavour of malignant melanoma. Int J Cancer 104: 527-532, 2003.

40. Park JY, Ryang YS, S KY, et al: Molecular signaling cascade in DNA bisintercalator, echinomycin-induced apoptosis of HT29 cells. Evidence of the apoptotic process via activation of the cytochrome-c-ERK-caspase-3 pathway. Int J Biochem Cell Biol 28: 244-254, 2006 